\title{
Ärztliche Hilfe für das südliche Afrika
}

\section{Paul Mühlhauser}

Dr. med., Facharzt für Innere Medizin, Landarzt in Plaffeien FR

Gib einem Hungernden einen Fisch, und er wird einmal satt, lehre ihn Fischen, und er wird nie wieder hungern.

(nach Laotse)

$\mathrm{Zu}$ Beginn dieses Jahres wurde der Verein Mudiro gegründet mit dem Ziel, im Norden Namibias die medizinische Versorgung der Bevölkerung zu verbessern. In der Tat sind dort die Menschen zwar in der glücklichen Lage, am Grenzfluss zu Angola zu wohnen, der sehr viel Wasser führt und somit Fruchtbarkeit mit sich bringt; aber über das Wasser verbreiten sich auch tropische Krankheiten. Die Wohlhabenden besitzen eine kleine Kuhherde und ähnlich wie in der Schweiz des 18. Jahrhunderts geht es diesen Leuten damit relativ gut. Wer stattdessen einige Ziegen hat, mag noch passabel über die Runden kommen. Wirklich arm sind jene, die dieses Glück nicht haben. Neben übertragbaren tropischen Krankheiten birgt der Fluss auch andere Gefahren. Krokodil-Angriffe machen das Wasser Holen gefährlich, viele Kinder sterben an Malaria, und nicht zuletzt sind in Namibia ca. 20 Prozent der Bevölkerung mit AIDS infiziert. Einige Menschen leiden zudem an Tuberkulose. Namibia hat erst dieses Jahr damit begonnen Ärzte auszubilden. Somit findet man in den Spitälern einen bunten Mix aus Ärzten aller Welt, die Bewundernswertes leisten, aber in vielen Belangen suboptimal auf ihre Aufgaben vorbereitet wurden.

So wurde ich von der Vereinsgründerin Barbara Müller, Vertreterin unseres Material-Lieferanten Optipharm, eingeladen, an der zweiten Mission teilzunehmen. Ein lang gehegter Wunsch von mir wurde wahr, einmal meine Kraft und mein Können an eine Bevölkerung weiterzugeben, die weniger gut da steht.

Ziel der viermal jährlich für einen bis zwei Monate stattfindenden Einsätze von Mudiro ist es, in einem bestimmten Gebiet einen kleinen Fortschritt zu bewirken und die Ärzte in der Sprechstunde und auf dem Notfall zu unterstützen.

Ich hatte die Aufgabe, Ärzte für Ultraschalluntersuchungen vom Abdomen zu schulen. Sonographie ist schon bei uns ein sehr wirksames Werkzeug in der Hand eines Allgemeinmediziners. In den 20 Jahren meiner Hausarzttätigkeit konnte ich nach einer guten Schulung 8000 Untersuchungen durchführen, und es war eine Freude festzustellen, wie nützlich sich diese Kenntnisse in Namibia umsetzen lassen und wie rasch die Ärzte dort Fortschritte gemacht haben. In zwei Spitälern haben wir täglich insgesamt mit sechs Ärzten

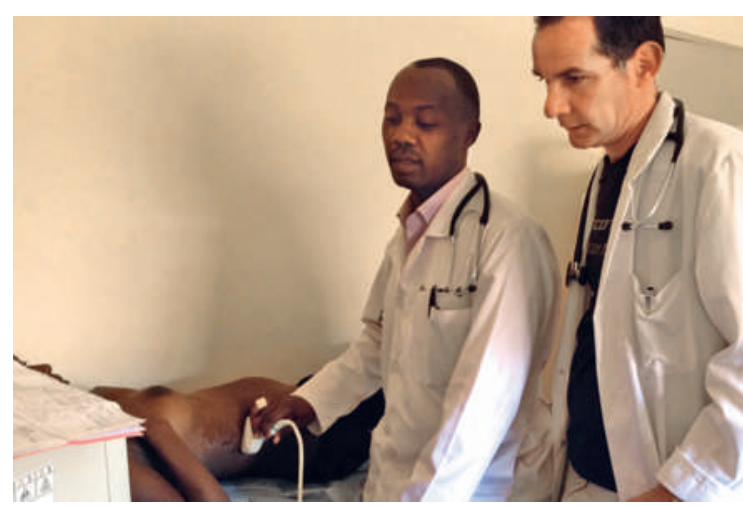

Paul Mühlhauser gibt einheimischen Ärzten sein Wissen über Ultraschalluntersuchungen weiter.

zehn Untersuchungen machen können. Somit konnten in den fünf Wochen meines Einsatzes nicht nur 250 Patienten besser behandelt werden, sondern diese Ärzte werden dank dem erlernten systematischen Vorgehen künftig viel effizienter arbeiten können.

In einem dritten Spital in Rundu, in der zweitgrössten Stadt des Landes, wurde ich bei einem Besuch gebeten, auch für Schulungszwecke zur Verfügung zu stehen. Mit den zwei vorhandenen Apparaten kann das medizinische Personal nicht umgehen, da niemand die Mitarbeitenden in der korrekten Handhabung unterwiesen hatte.

So habe ich entschieden, meine Sommerferien für diesen Zweck aufzuopfern. Ferien sollen ja auch der Abwechslung dienen, und wenn ich es mit etwas Nützlichem verbinden kann, dann umso besser. Gedankt wird einem dadurch, dass einem bewusst wird, dass einiges Leid gelindert werden kann - nebst der Tatsache, dass man interessante Fälle sieht. Daneben wird man von der unglaublich schönen Natur beglückt, dem Lächeln der Kinder und der Dankbarkeit des Spitalpersonals, das froh um jede Hilfe ist, so gering sie auch sein mag. Ich kann jeden Arzt ermuntern, einen solchen Einsatz zu machen; es hilft die Probleme unseres Praxisalltages sehr zu relativieren. Es wird einem klar, auf wie hohem Niveau wir Schweizer klagen, und hilft den Druck, den uns die Patienten, aber auch oft wir selbst uns auferlegen, abzubauen.

\section{Weitere Informationen zu Mudiro}

Mehr Informationen unter www.mudiro.com oder bei Barbara Müller (barbara.mueller[at]optipharm.ch).

Ein Informationsabend zu Mudiro findet am 8.10.2015 um 19.30 Uhr in Bern statt. Anmelden können sich interessierte Ärzte unter barbara.mueller[at]optipharm.ch 